ARTICLE

Received 20 Feb 2015 | Accepted 14 Sep 2015 | Published 21 Oct $2015 \quad$ DOl: 10.1038/ncomms9647 OPEN

\title{
Molecular co-catalyst accelerating hole transfer for enhanced photocatalytic $\mathrm{H}_{2}$ evolution
}

Wentuan $\mathrm{Bi}^{1}{ }^{1 \star \star}$, Xiaogang $\mathrm{Li}^{1, \star}$, Lei Zhang ${ }^{1, \star}$, Tao Jin ${ }^{1}$, Lidong Zhang ${ }^{2}$, Qun Zhang ${ }^{1}, \mathrm{Yi}_{\mathrm{i}} \mathrm{Luo}^{1}$, Changzheng $\mathrm{Wu}^{1}$ $\& Y i X_{i e}^{1}$

In artificial photocatalysis, sluggish kinetics of hole transfer and the resulting high-charge recombination rate have been the Achilles' heel of photocatalytic conversion efficiency. Here we demonstrate water-soluble molecules as co-catalysts to accelerate hole transfer for improved photocatalytic $\mathrm{H}_{2}$ evolution activity. Trifluoroacetic acid (TFA), by virtue of its reversible redox couple TFA॰/TFA ${ }^{-}$, serves as a homogeneous co-catalyst that not only maximizes the contact areas between co-catalysts and reactants but also greatly promotes hole transfer. Thus $\mathrm{K}_{4} \mathrm{Nb}_{6} \mathrm{O}_{17}$ nanosheet catalysts achieve drastically increased photocatalytic $\mathrm{H}_{2}$ production rate in the presence of TFA, up to 32 times with respect to the blank experiment. The molecular co-catalyst represents a new, simple and highly effective approach to suppress recombination of photogenerated charges, and has provided fertile new ground for creating high-efficiency photosynthesis systems, avoiding use of noble-metal co-catalysts.

\footnotetext{
${ }^{1}$ Hefei National Laboratory for Physical Sciences at the Microscale, Collaborative Innovation Center of Chemistry for Energy Materials, Synergetic Innovation Center of Quantum Information and Quantum Physics, Hefei Science Center of CAS, CAS Key Laboratory of Mechanical Behavior and Design of Materials, University of Science and Technology of China, Hefei 230026, Anhui, China. ${ }^{2}$ National Synchrotron Radiation Laboratory, University of Science and Technology of China, Hefei 230026, Anhui, China. * These authors contributed equally to this work. Correspondence and requests for materials should be addressed to C.W. (email: czwu@ustc.edu.cn) or to Q.Z. (email: qunzh@ustc.edu.cn).
} 
P hotocatalytic conversion of solar energy to fuels is considered to be an ideal, renewable energy resource for the future, yet the relatively low-energy conversion efficiency remains the most critical factor that limits its practical applications ${ }^{1-4}$. In principle, the generation of electron-hole pairs in photocatalysts upon illumination and their participation in subsequent redox reactions are the main processes among the widely investigated photocatalytic reactions. To achieve highly efficient photochemical conversion, the main challenge in photocatalysis is to maximize the extraction of charge carriers while suppressing their recombination ${ }^{5,6}$. Arguably, the electron transfer is typically sufficiently fast, whereas the transport of hole and subsequent reactions are generally slow, eventually leading to the high-charge recombination rate $^{7-9}$. From this perspective, accelerating hole transfer kinetics, typically the rate-limiting step, has emerged as the inevitable route to achieve high-efficiency charge separation.

Co-catalysts are known to provide trapping sites for the photogenerated charges and promote charge separation ${ }^{10,11}$. Noble-metal oxides (such as $\mathrm{RuO}_{2}$ and $\mathrm{IrO}_{2}$ ) are usually used as co-catalysts for hole transport because they can effectively lower the overpotential for the oxidation reaction. Meanwhile, subjected to their high costs of upscaling, several cost-effective and earth-abundant alternatives (primarily based on Co- $\mathrm{Pi}, \mathrm{NiO}_{x}$, $\mathrm{CoO}_{x}$, and so on) have also been exploited and achieve relatively high efficiency. However, this strategy through solid-state co-catalysts loading is potentially limited by finite contact areas between co-catalysts and reactants, lacking sufficient active sites for catalysis.

Alternatively, homogeneous catalysis, free from limited contact areas, has gained considerable attention due to its high activity and selectivity ${ }^{12}$. For example, biological hydrogenases and their artificial mimics as well as the newly developed transitionmetal complexes are regarded as a class of novel $\mathrm{H}_{2}$-evolution catalysts $^{13,14}$. The inspiration gained from $\mathrm{Mn}_{4} \mathrm{CaO}_{5}$ clusters of photosystem II in natural photosynthesis also stimulates the exploitation of $\mathrm{O}_{2}$-evolution catalysts ${ }^{15}$. Catalysts of this type have demonstrated impressive achievements in artificial photocatalysis. Nevertheless, note that most of these photocatalytic processes must be carried out in organic systems due to the poor water solubility and low stability of organometallic molecules, which is neither economical nor environmentally benign. To this end, developing water-soluble co-catalysts in photocatalytic systems is indispensable to achieve cost-effective and highly efficient artificial photocatalysis.

In this article, we propose a water-soluble molecular co-catalyst strategy to accelerate the hole transfer kinetics. The reversible redox couple $\mathrm{TFA} \bullet / \mathrm{TFA}^{-}$, making trifluoroacetic acid molecule (TFA) a robust molecular co-catalyst, provides further charge separation pathway across the catalysts interface, and consequently facilitates photocatalytic $\mathrm{H}_{2}$ generation. In situ electron spin resonance (ESR) together with energy-level alignment reveal that photogenerated holes in $\mathrm{K}_{4} \mathrm{Nb}_{6} \mathrm{O}_{17}$ valence band readily react with the adsorbed TFA anions to yield TFA radicals and simultaneously the highly reactive radicals transfer holes to methanol, eliminating the main competitive pathway of electron-hole recombination. Moreover, ultrafast transient absorption spectroscopy combined with static as well as time-resolved photoluminescence spectroscopy confirms that effective charge separation is the primary factor behind the dramatically improved photocatalytic performance. Homogeneous co-catalyst, which is free from the limited contact areas between co-catalysts and reactants, provides sufficient active sites for catalysis, thus offering new opportunity to develop high-efficiency photosynthesis.

\section{Results}

$\mathrm{K}_{4} \mathrm{Nb}_{6} \mathrm{O}_{17}$ nanosheets. Layered niobate is a well-accepted photocatalytic system for water splitting, and its unique layered structure has boosted new opportunities for the manipulation of two-dimensional nanomaterials by intercalation and delamination ${ }^{4,16-18}$. Benefiting from the highly anisotropic structure, niobate ultrathin nanosheets allow advances in potentially exposing more reactive sites and facilitating the contact of catalysts with reactants, and thus provide an ideal platform for artificial photocatalysis. Here $\mathrm{K}_{4} \mathrm{Nb}_{6} \mathrm{O}_{17}$ nanosheet catalysts were synthesized via a conventional solution method by anisotropic growth ${ }^{19}$. The as-synthesized $\mathrm{K}_{4} \mathrm{Nb}_{6} \mathrm{O}_{17}$ catalysts showed a typical nanosheet morphology with lateral size varied from 100 to $500 \mathrm{~nm}$, as shown by scanning electron microscopy (SEM) and transmission electron microscopy (TEM; Supplementary Fig. 1). In addition, the well-resolved lattice features in high-resolution transmission electron microscope (HRTEM) image revealed the high crystallinity of these nanosheets and the interplanar distances coincided well with that of (200) and (002) facets respectively.

Photocatalytic performance. As illustrated in Fig. 1, the reversible redox couple TFA॰/TFA ${ }^{-}$and the highly active intermolecular radical reactions make TFA molecule a robust hole shuttle, effectively promoting the charge separation of $\mathrm{K}_{4} \mathrm{Nb}_{6} \mathrm{O}_{17}$ catalysts, and thus leading to improved photocatalytic activity. Figure $2 \mathrm{a}$ shows the comparison of $\mathrm{H}_{2}$ evolution rates on $\mathrm{K}_{4} \mathrm{Nb}_{6} \mathrm{O}_{17}$ nanosheet catalysts with extra addition of different amounts of TFA as molecular co-catalyst. $\mathrm{K}_{4} \mathrm{Nb}_{6} \mathrm{O}_{17}$ nanosheets alone showed low activity in photocatalytic $\mathrm{H}_{2}$ evolution (ca.195 $\mu \mathrm{molg}^{-1} \mathrm{~h}^{-1}$ ). Notably, when TFA as co-catalyst was added, the $\mathrm{H}_{2}$ evolution activity turned out to be dramatically

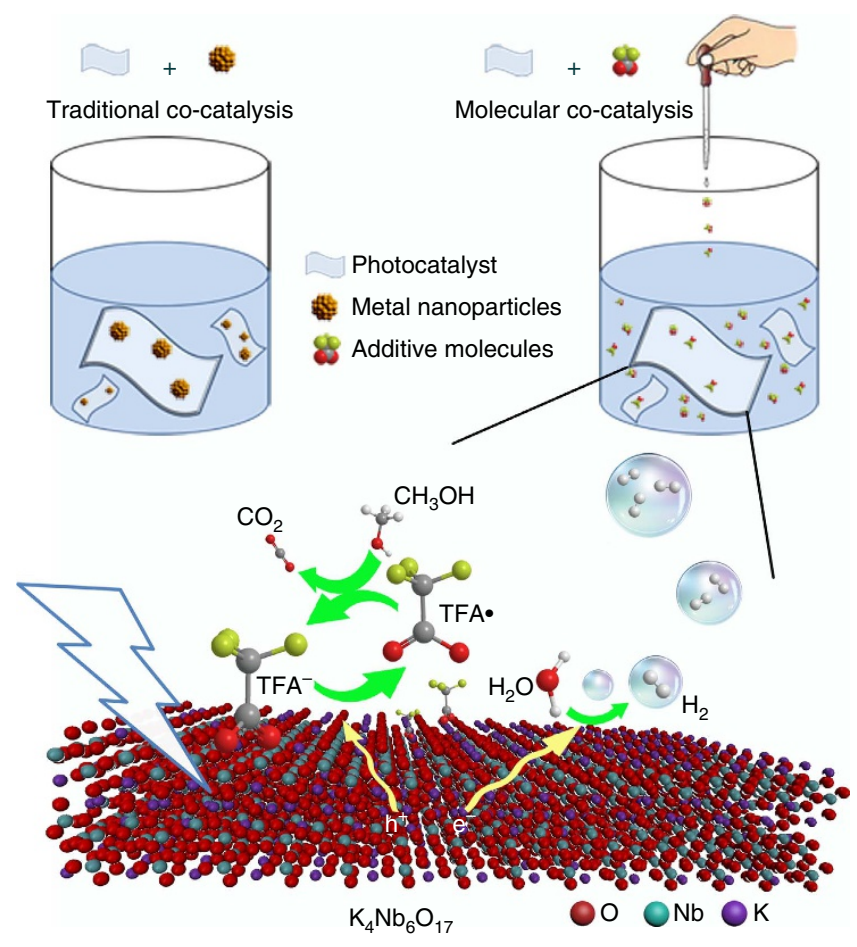

Figure 1 | Schematic illustration of molecular co-catalyst strategy for accelerating hole transfer. Homogeneous molecular co-catalysts use reversible redox couple and highly active free radical reactions to promote hole transport, unlike supported heterogeneous co-catalysts, which is constrained by finite contact areas between co-catalysts and reactants. Purple, cyan and red spheres denote $\mathrm{K}, \mathrm{Nb}$ and $\mathrm{O}$ atoms, respectively. 

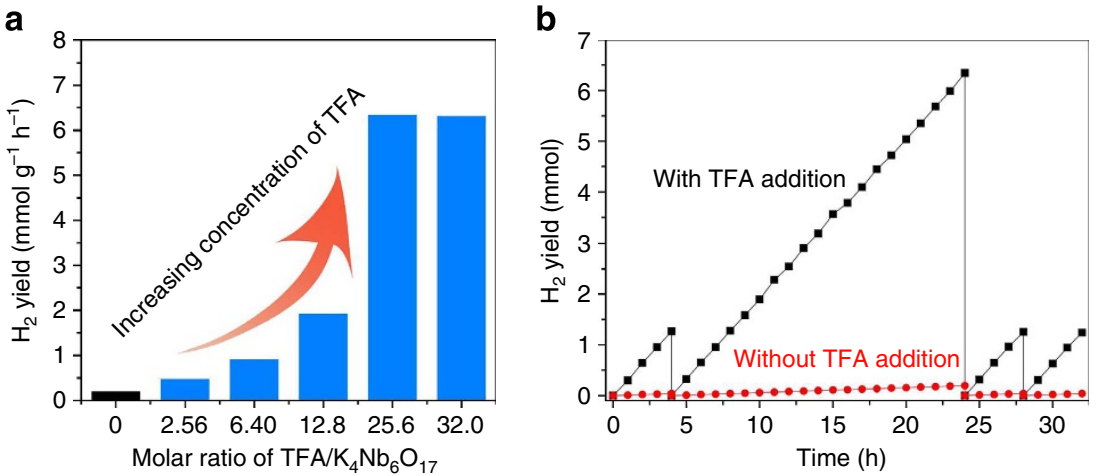

Figure 2 | Photocatalytic $\mathbf{H}_{\mathbf{2}}$ production performance. (a) Photocatalytic activity on $\mathrm{K}_{4} \mathrm{Nb}_{6} \mathrm{O}_{17}$ nanosheet catalysts with different molar ratio of TFA $/ \mathrm{K}_{4} \mathrm{Nb}_{6} \mathrm{O}_{17}$. (b) Cycle stability test on $\mathrm{K}_{4} \mathrm{Nb}_{6} \mathrm{O}_{17}$ nanosheet catalysts with $100 \mu \mathrm{l}$ TFA addition. Reaction condition: $50 \mathrm{mg}$ catalyst, $200 \mathrm{ml} 20$ vol\% methanol aqueous solution and a specific amount of TFA, under irradiation of a $300 \mathrm{~W}$ Xe lamp.

enhanced. Substantial increase of $\mathrm{H}_{2}$ evolution rates was observed with the molar ratio of TFA/ $\mathrm{K}_{4} \mathrm{Nb}_{6} \mathrm{O}_{17}$ ranging from 2.56 to 25.6 , reaching a maximum value of $6,344 \mu \mathrm{molg}^{-1} \mathrm{~h}^{-1}$, up to 32 times with respect to that of bare $\mathrm{K}_{4} \mathrm{Nb}_{6} \mathrm{O}_{17}$ nanosheets without TFA. Notably, increasing the molar ratio of $\mathrm{TFA} / \mathrm{K}_{4} \mathrm{Nb}_{6} \mathrm{O}_{17}$ above 25.6 did not bring about further obvious increase for photocatalytic performance which is probably due to the saturated adsorption of TFA molecules on the surface of $\mathrm{K}_{4} \mathrm{Nb}_{6} \mathrm{O}_{17}$ catalysts, as confirmed by elemental analysis in Supplementary Table 1 and Supplementary Note 1 . In a word, niobate photocatalyst achieved a significantly improved $\mathrm{H}_{2}$ generation rate when water-soluble TFA molecule was used as co-catalyst.

Recycling test of photocatalytic $\mathrm{H}_{2}$ evolution on the $\mathrm{K}_{4} \mathrm{Nb}_{6} \mathrm{O}_{17}$ nanosheet catalysts with addition of $100 \mu \mathrm{l}$ TFA was performed to evaluate the photocatalytic stability during a long-term photocatalytic reaction. As shown in Fig. $2 \mathrm{~b}$, the respective total amount of $\mathrm{H}_{2}$ after $20 \mathrm{~h}$ illumination was $6.344 \mathrm{mmol}$ and no noticeable degradation was detected during the four consecutive reactions, which indicates the high stability of $\mathrm{K}_{4} \mathrm{Nb}_{6} \mathrm{O}_{17}$ catalysts and that no obvious side reactions associated with TFA consumption occurred during the photocatalytic process. The reversibility of TFA was further verified by ${ }^{19} \mathrm{~F}$ NMR. As illustrated in Supplementary Fig. 2 and Supplementary Note 2, no new fluoride species were detected after the reaction. And according to the quantitative characterization results, the concentration of TFA remains constant during the whole photocatalytic process.

To disclose the role of TFA molecules in the photocatalytic $\mathrm{H}_{2}$ evolution reaction, a series of control experiments were carried out for comparison. Control experiment without methanol but with only $100 \mu \mathrm{l}$ TFA (Supplementary Fig. 3a) showed a relatively low activity in photocatalytic $\mathrm{H}_{2}$ evolution (ca. $158 \mu \mathrm{molg}^{-1} \mathrm{~h}^{-1}$ ), indicating a synergistic effect exists between TFA molecules and $\mathrm{CH}_{3} \mathrm{OH}$. Meanwhile, to rule out the influence from the changes of hydrogen ion concentration induced by TFA addition, we systematically investigated the $\mathrm{pH}$ effect by adjusting $\mathrm{pH}$ values of the solution with $1 \mathrm{M} \mathrm{HCl}$. As shown in Supplementary Fig. $3 \mathrm{~b}$, the $\mathrm{H}_{2}$ evolution rates were found to slightly increase with decreasing the $\mathrm{pH}$ values, but well below $600 \mu \mathrm{molg}^{-1} \mathrm{~h}^{-1}$. These results indicate that TFA indeed directly participated in the photocatalytic reaction process, rather than determining the $\mathrm{pH}$ value of the catalytic system only. Based on the above control experiments, it is found that the added TFA should be responsible for the significant performance improvement of photocatalytic system, in which TFA molecules recycle stoichiometrically during the reaction process.
$\mathrm{K}_{4} \mathrm{Nb}_{6} \mathrm{O}_{17}$ nanosheets upon TFA addition. To gain in-depth insight into the origin of the improved photocatalytic activity, we compared the morphology, crystalline structure, surface chemical states and optical properties of the $\mathrm{K}_{4} \mathrm{Nb}_{6} \mathrm{O}_{17}$ nanosheets with/ without addition of TFA after the catalytic reaction. SEM and TEM images in Supplementary Fig. 1 revealed that $\mathrm{K}_{4} \mathrm{Nb}_{6} \mathrm{O}_{17}$ catalysts still kept the initial nanosheet morphology after reaction. X-ray powder diffraction and HRTEM further confirmed structural maintenance. High-resolution X-ray photoelectron spectroscopy analysis of the $\mathrm{K}_{4} \mathrm{Nb}_{6} \mathrm{O}_{17}$ nanosheet catalysts after TFA addition (Supplementary Fig. 4a) showed an additional peak at $688.6 \mathrm{eV}$ which can be attributed to the $-\mathrm{CF}_{3}$ groups, indicating the preferential adsorption of TFA on the surface of $\mathrm{K}_{4} \mathrm{Nb}_{6} \mathrm{O}_{17}$ nanosheets ${ }^{20}$. The optical properties were measured using ultraviolet-visible absorption spectra in the wavelength range of 220-800 nm (Supplementary Fig. 4b). The absorption edge of $\mathrm{K}_{4} \mathrm{Nb}_{6} \mathrm{O}_{17}$ nanosheet catalysts was observed at $\sim 348 \mathrm{~nm}$, corresponding to a bandgap of $3.56 \mathrm{eV}$. Upon TFA addition, a weak absorption enhancement in the ultraviolet region was observed, which probably originates from the absorption of TFA itself, whereas the absorption edge of photocatalysts showed no noticeable shift. This result demonstrates that the improved photocatalytic performance cannot be ascribed to the enhancement of light absorption, but instead to the effective charge separation.

TA and PL analyses. To evaluate how the addition of TFA affects the charge separation behaviour involved in the $\mathrm{K}_{4} \mathrm{Nb}_{6} \mathrm{O}_{17}$ nanosheet catalysts, we interrogated the $\mathrm{K}_{4} \mathrm{Nb}_{6} \mathrm{O}_{17}$ and $\mathrm{K}_{4} \mathrm{Nb}_{6} \mathrm{O}_{17}$-TFA samples by means of ultrafast transient absorption (TA) spectroscopy, which is known as a robust tool for tracking in real-time charge carrier dynamics in nanosystems ${ }^{21}$. In our TA measurements, a femtosecond ultraviolet pump/white-light continuum probe scheme was employed (see Supplementary Methods for details of the pump-probe experiments). The centre wavelength of the pump pulses was chosen at $300 \mathrm{~nm}$, which can effectively photo-induce an interband transition in the semiconductor $\mathrm{K}_{4} \mathrm{Nb}_{6} \mathrm{O}_{17}$ system (refer to Supplementary Fig. 4b). Since the $390-610 \mathrm{~nm}$ white-light continuum probe was found to yield essentially the same TA kinetics for each sample, we show here a set of representative data taken at $500 \mathrm{~nm}$ (Fig. 3a,b). It turned out that both samples exhibited TA signals due to photoinduced absorption, whose relaxation can be characterized by two time constants: $\tau_{1}=7 \pm 1$ ps and $\tau_{2}=219 \pm 18$ ps for $\mathrm{K}_{4} \mathrm{Nb}_{6} \mathrm{O}_{17}$ while $\tau_{1}=10 \pm 2$ ps and $\tau_{2}=522 \pm 62$ ps for $\mathrm{K}_{4} \mathrm{Nb}_{6} \mathrm{O}_{17}-\mathrm{TFA}$ (all with a roughly 40:60 percentage for the two exponential components). Note that the long-time decay component(s) cannot be identified 
a

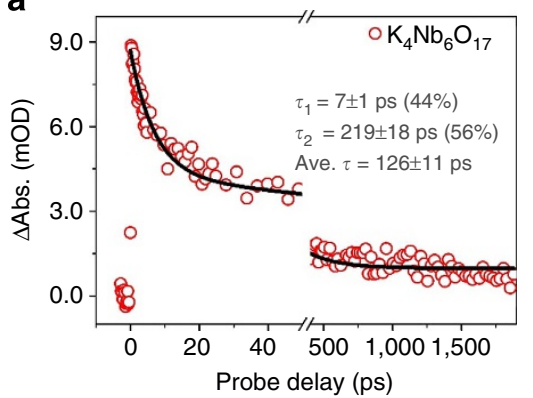

C

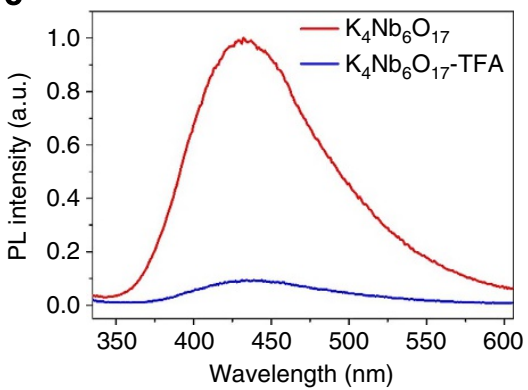

b

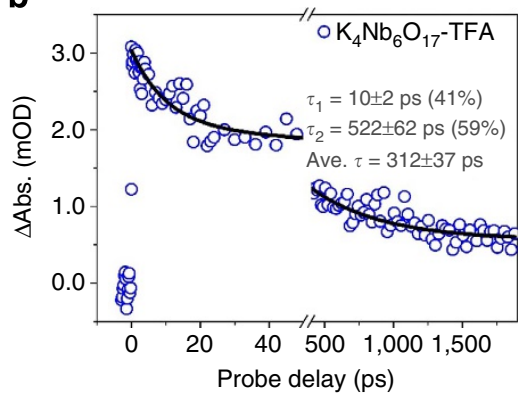

d

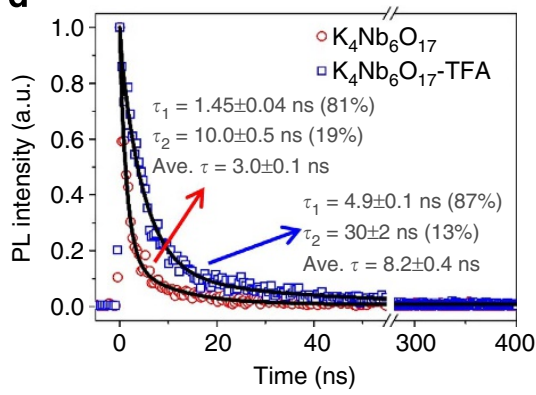

e

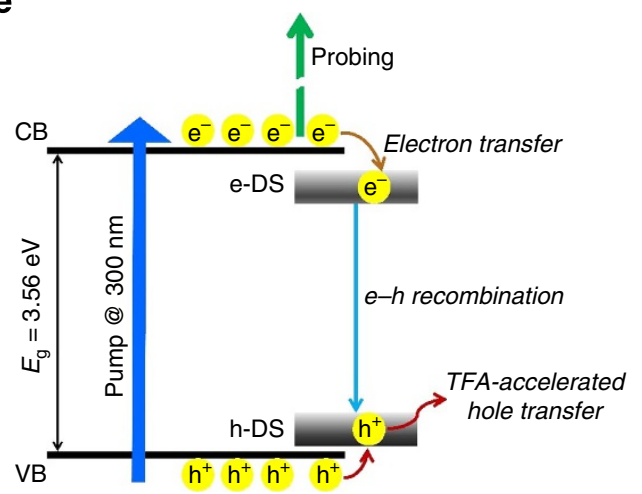

Figure 3 | Spectroscopic evidence for effective charge separation process. Representative ultrafast TA kinetics probed at $500 \mathrm{~nm}$ (pump at $300 \mathrm{~nm}$ ) for $\mathrm{K}_{4} \mathrm{Nb}_{6} \mathrm{O}_{17}$ nanosheets in the (a) absence and (b) presence of TFA. The TA signal (that is, the absorbance changes, or $\triangle \mathrm{Abs}$. in short) is given in mOD where OD stands for optical density. (c) PL emission and (d) time-resolved PL spectra (excitation at $315 \mathrm{~nm}$, emission at $430 \mathrm{~nm}$ ) for both $\mathrm{K}_{4} \mathrm{Nb}_{6} \mathrm{O}_{17}$ and $\mathrm{K}_{4} \mathrm{Nb}_{6} \mathrm{O}_{17}-\mathrm{TFA}$. (e) Schematic illustration of the mechanisms involved; see text for details.

due to the probe-delay limit of our pump-probe spectrometer (ca. 2 ns). The observed two components in the picosecond domain may reflect the electron dynamics associated with the defect states that are energetically located within the bandgap. Considering that such defect states could be long-lived (in the nanosecond domain), we resorted to photoluminescence (PL) spectroscopy. It is clearly seen from the PL spectra excited at $315 \mathrm{~nm}$ (Fig. 3c) that the addition of TFA results in substantial PL quenching, indicating greatly suppressed radiative electron-hole recombination in $\mathrm{K}_{4} \mathrm{Nb}_{6} \mathrm{O}_{17}$-TFA with respect to $\mathrm{K}_{4} \mathrm{Nb}_{6} \mathrm{O}_{17}$. Figure $3 \mathrm{~d}$ compares the $\mathrm{PL}$ lifetimes recorded for the two samples at the emission wavelength of $430 \mathrm{~nm}$ (that is, the PL intensity maximum in Fig. 3c). Notably, two lifetimes with sizable components, as in the TA kinetics measurements, were observed for both samples: $\tau_{1}=1.45 \pm 0.04 \mathrm{~ns}(81 \%)$ and $\tau_{2}=10.0 \pm 0.5 \mathrm{~ns}$ (19\%) for $\mathrm{K}_{4} \mathrm{Nb}_{6} \mathrm{O}_{17}$ while $\tau_{1}=4.9 \pm 0.1 \mathrm{~ns} \quad(87 \%)$ and $\tau_{2}=30 \pm 2 \mathrm{~ns}(13 \%)$ for $\mathrm{K}_{4} \mathrm{Nb}_{6} \mathrm{O}_{17}-\mathrm{TFA}$.

On the basis of the combined TA and PL observations, we illustrate in Fig. 3e the schematic mechanisms underlying the photoexcited carrier dynamics involved in the system. The observed PL emissions peaking at ca. $430 \mathrm{~nm}$ (that is, $2.88 \mathrm{eV}$, red-shifted with respect to the $3.56-\mathrm{eV}$ bandgap) with two PL lifetimes suggest that the radiative electron-hole recombination responsible for PL could originate from two interfacial defect states (probably with different trap depths) near the conduction band (CB) bottom (labelled e-DS as a whole in Fig. 3e) that act as the $\mathrm{PL}$ emission centres ${ }^{22}$. These defect states receive and accumulate the photogenerated electrons transferred from the $\mathrm{CB}$ bottom in a bi-exponential relaxation manner, as evidenced by the observed TA kinetics which are obviously commensurate with the time-resolved PL results. On the other hand, the photogenerated holes are transferred from the valence band (VB) to the defect states near the VB top (labelled h-DS in Fig. 3e). The addition of TFA can be expected to accelerate the subsequent hole transfer from h-DS to hole scavengers in the solution (including methanol as well as TFA itself). This is understandable because the situation of h-DS being effectively vacated via the TFA anion-accelerated hole transfer will eventually decelerate the processes of electron-hole recombination and electron transfer from CB to e-DS, as verified by our observed, significantly altered carrier dynamics. It is worth stressing here that, in the presence of TFA, the average time describing the overall electron transfer from CB to e-DS is increased by a factor of ca. $2.48(312 \pm 37 \mathrm{ps}$ for $\mathrm{K}_{4} \mathrm{Nb}_{6} \mathrm{O}_{17}-\mathrm{TFA}$ versus $126 \pm 11 \mathrm{ps}$ for $\left.\mathrm{K}_{4} \mathrm{Nb}_{6} \mathrm{O}_{17}\right)$ and 
meanwhile that describing the overall radiative $\mathrm{e}-\mathrm{h}$ recombination by a factor of ca. $2.73 \quad(8.2 \pm 0.4 \mathrm{~ns}$ for $\mathrm{K}_{4} \mathrm{Nb}_{6} \mathrm{O}_{17}$-TFA versus $3.0 \pm 0.1 \mathrm{~ns}$ for $\mathrm{K}_{4} \mathrm{Nb}_{6} \mathrm{O}_{17}$ ). Based on the self-consistent results of PL and TA observations (see insets in Fig. 3 for details), it is understandable that TFA mainly influences the hole transport process. And it can be safely inferred that the increased electron lifetimes in the system could offer more opportunities for photogenerated electrons to participate in the $\mathrm{H}^{+}$reduction reaction.

In situ ESR characterizations. To better understand the photocatalytic process of $\mathrm{H}_{2}$ production in the presence of TFA, ESR technique using 5,5-dimethyl-1-pyrroline $N$-oxide (DMPO) as a trapping regent was used to in situ monitor the intermediates. Under ultraviolet irradiation, the typical ESR spectrum of the catalysts aqueous suspensions containing only TFA is presented in Fig. $4 \mathrm{a}$, which is composed of 10 lines with hyperfine constants $\mathrm{aN}=15.5 \mathrm{G}, \mathrm{aH}_{\beta}=18 \mathrm{G}$, and $\mathrm{aF}=3.6 \mathrm{G}$. These parameters exactly match the simulated ESR spectrum of DMPO- $\mathrm{CF}_{3} \mathrm{COO}$ adducts $^{23}$. Control experiments in Supplementary Fig. 5 and Supplementary Note 3 also confirmed that DMPO- $\mathrm{CF}_{3} \mathrm{COO}$ adducts were formed via the reaction of DMPO with TFA radicals. Meanwhile, signal quenching was observed immediately when the light source was turned off, reflecting the high reactivity of $\mathrm{DMPO}-\mathrm{CF}_{3} \mathrm{COO}$ adducts. Under the same illumination conditions, methanol aqueous solution with $\mathrm{K}_{4} \mathrm{Nb}_{6} \mathrm{O}_{17}$

\section{a}

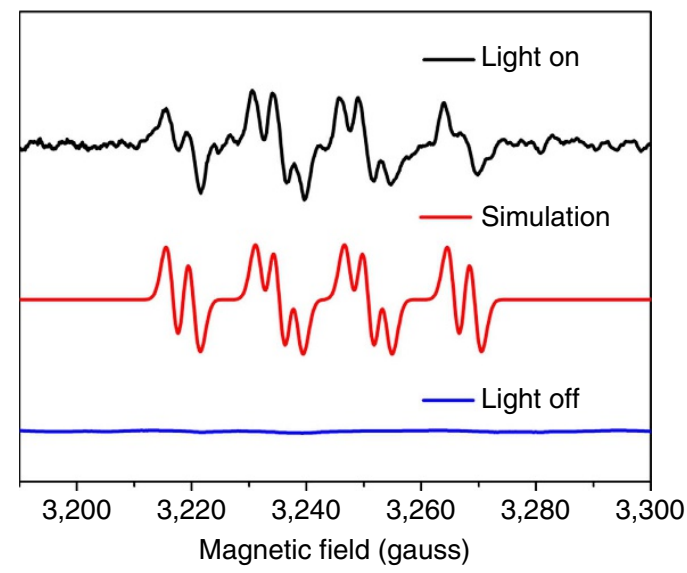

b

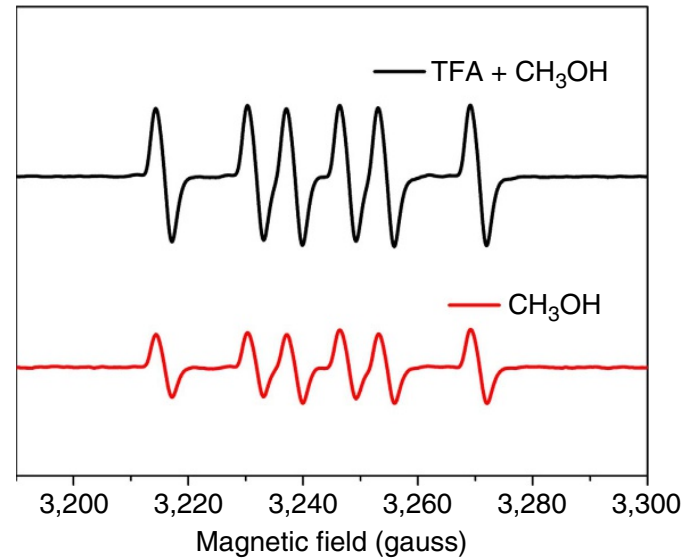

Figure 4 | In situ ESR on intermediates. ESR spectra of the radicals using DMPO as the spin trapping agent (a) in $\mathrm{K}_{4} \mathrm{Nb}_{6} \mathrm{O}_{17}$ aqueous suspensions with addition of TFA; (b) in $\mathrm{K}_{4} \mathrm{Nb}_{6} \mathrm{O}_{17}$ aqueous suspensions with the presence of methanol, or methanol and TFA. nanosheet catalysts gave rise to a six-lined spectrum, which can be assigned to the DMPO- $\mathrm{CH}_{3}$ adducts ${ }^{24}$. However, as for the mixture of TFA and methanol aqueous solution, the spectrum kept the same as that in methanol aqueous solution except for a higher signal intensity, which is seen in Fig. 4b. Analogously to the reported DMPO- $\mathrm{CH}_{3}$ adducts formation process via the reaction of DMPO-OH adducts with dimethylsulfoxide ${ }^{24,25}$, the failure to observe the $\mathrm{DMPO}-\mathrm{CF}_{3} \mathrm{COO}$ spin adducts signal may result from the ultrafast electron transfer from $\mathrm{CH}_{3} \mathrm{OH}$ to TFA radicals, accompanied by the generation of methyl radicals and TFA anions. Moreover, this interpretation is, in fact, substantiated by the increased intensity of $\mathrm{DMPO}-\mathrm{CH}_{3}$ adducts in Fig. 4b. Based on these ESR results, it is reasonable to assert that the reversible $\mathrm{TFA} \bullet / \mathrm{TFA}^{-}$reaction eliminates the main competitive pathway of electron-hole recombination and accelerates the oxidation of methanol, eventually promoting the hole transport process.

\section{Discussion}

Energy-level alignment illustrated in Fig. 5 provides further theoretical evidence for the above photocatalytic mechanism. According to the previous reports ${ }^{26,27}$, the flat-band potential is located just below the bottom of $\mathrm{CB}$ for an $n$-type semiconductor. Thus the $\mathrm{CB}$ potential of $\mathrm{K}_{4} \mathrm{Nb}_{6} \mathrm{O}_{17}$ is estimated to be $-0.52 \mathrm{~V}$ (versus normal hydrogen electrode (NHE), $\mathrm{pH} \sim 7$, Supplementary Fig. 6), in agreement with the previous report ${ }^{17,28}$. Given the bandgap of $3.56 \mathrm{eV}$, the $\mathrm{VB}$ maximum is located at

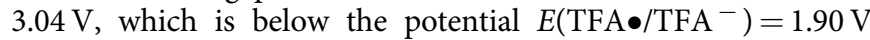
(Supplementary Methods) at $\mathrm{pH}=7$. Therefore, the holes in $\mathrm{K}_{4} \mathrm{Nb}_{6} \mathrm{O}_{17}$ interfaces are able to readily react with the adsorbed TFA anions to yield TFA radicals, confirming the feasibility of TFA radicals as reactive intermediates. Meanwhile, the oxidation potential of $\mathrm{CH}_{3} \mathrm{OH}^{29},-0.39 \mathrm{~V}$ (versus $\mathrm{NHE}, \mathrm{pH} \sim 7$ ), is well above $E\left(\mathrm{TFA} \bullet / \mathrm{TFA}^{-}\right)$. As such, $\mathrm{CH}_{3} \mathrm{OH}$ can provide electrons to reduce the highly reactive TFA radicals. In this regard, TFA molecules stand out as recyclable co-catalysts for facilitating hole transport. Given the additional charge separation pathway across the solid-liquid interface and the extremely rapid intermolecular radical reactions, charge recombination can be effectively

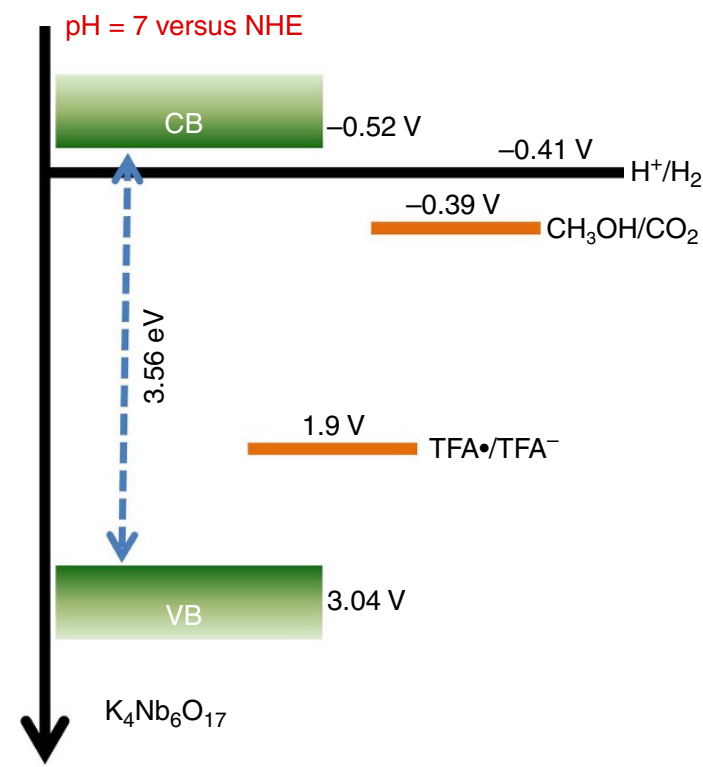

Figure 5 | Theoretical analysis for the molecular co-catalyst strategy. Schematic illustration of the energy diagram for the $\mathrm{K}_{4} \mathrm{Nb}_{6} \mathrm{O}_{17}$ nanosheet catalysts and the redox potentials of TFA and $\mathrm{CH}_{3} \mathrm{OH}$. NHE, normal hydrogen electrode. 
suppressed, and therefore more electrons can be released for water reduction.

On the other hand, loading Pt co-catalysts can further optimize the photocatalytic performance by promoting proton reduction reaction. As shown in Supplementary Fig. 7, the photocatalytic $\mathrm{H}_{2}$ generation rate of $\mathrm{Pt} / \mathrm{K}_{4} \mathrm{Nb}_{6} \mathrm{O}_{17}$ with the addition of TFA reached $9,116 \mu \mathrm{molg}^{-1} \mathrm{~h}^{-1}$, up to 46 times with respect to that of bare $\mathrm{K}_{4} \mathrm{Nb}_{6} \mathrm{O}_{17}$. Moreover, as in the aforementioned comparison of the self-consistent TA and time-resolved PL results of $\mathrm{K}_{4} \mathrm{Nb}_{6} \mathrm{O}_{17}$ and $\mathrm{K}_{4} \mathrm{Nb}_{6} \mathrm{O}_{17}-\mathrm{TFA}$, the similar comparison of $\mathrm{Pt} / \mathrm{K}_{4} \mathrm{Nb}_{6} \mathrm{O}_{17}$ and $\mathrm{Pt} / \mathrm{K}_{4} \mathrm{Nb}_{6} \mathrm{O}_{17}$-TFA (Supplementary Fig. 8 and Supplementary Note 4) further confirms that TFA mainly influences the hole transfer process. Besides, it is worth mentioning that the enhanced hole transport with TFA is applicable to other metal oxide photocatalysts. Taking layered titanate $\mathrm{Na}_{2} \mathrm{Ti}_{3} \mathrm{O}_{7}$ as an example, photocatalytic experiments confirmed the enhanced $\mathrm{H}_{2}$ evolution activity with the addition of TFA, which is shown in Supplementary Figs 9,10.

To disclose the essentials of molecular co-catalysts, acetic acid and oxalic acid were also investigated. As shown in Fig. 6a, they also led to improved $\mathrm{H}_{2}$ production performance in the first $4 \mathrm{~h}$, 15 and 12 times higher than that of bare $\mathrm{K}_{4} \mathrm{Nb}_{6} \mathrm{O}_{17}$ nanosheet catalysts, respectively. However, according to the ${ }^{1} \mathrm{H}$ NMR in Supplementary Fig. 11 and precipitation titration results in Supplementary Note 5, both acetic acid and oxalic acid underwent irreversible oxidation, which caused obvious decrease of $\mathrm{H}_{2}$ generation rate in the long-time photocatalytic experiment shown in Fig. 6b. These results demonstrate that the reversibility needs to be taken into account when designing molecular co-catalysts.
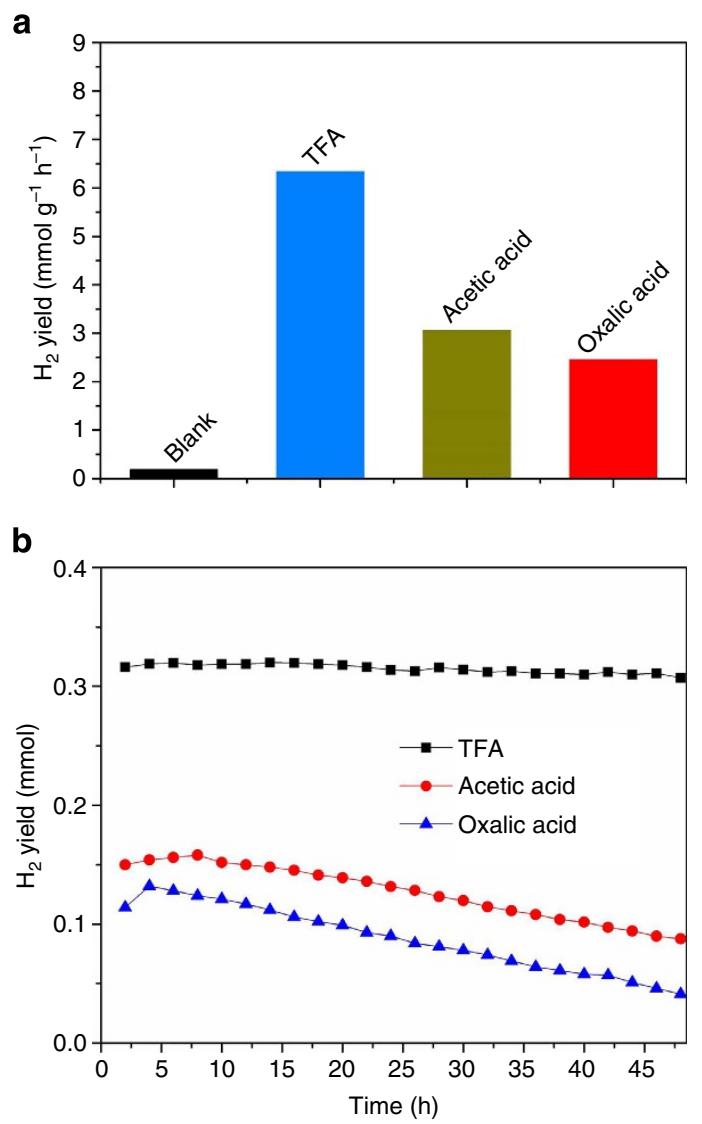

Figure 6 | The essentials of molecular co-catalysts. Comparison of photocatalytic $\mathrm{H}_{2}$ evolution activity for $\mathrm{K}_{4} \mathrm{Nb}_{6} \mathrm{O}_{17}$ catalysts with TFA, acetic acid, oxalic acid (a) in the first $4 \mathrm{~h}$, (b) every hour in the first $48 \mathrm{~h}$.
In conclusion, we have proposed an efficient molecular cocatalyst strategy to accelerate hole transfer kinetics while suppressing charge recombination. Benefiting from the reversible redox couple $\mathrm{TFA} \bullet / \mathrm{TFA}^{-}$and rapid intermolecular radical reactions, TFA molecule stands out as a homogeneous molecular co-catalyst, leading to a roughly two-fold increase of photoexcited-electron lifetime in niobate nanosheet photocatalytic system, thus eventually leading to a dramatically improved $\mathrm{H}_{2}$ generation rate of $6,344 \mu \mathrm{mol} \mathrm{g}^{-1} \mathrm{~h}^{-1}$, up to 32 times of that without the molecular co-catalyst. Altogether, the molecular co-catalyst strategy developed in this work provides a rational and cost-effective way for efficient separation of photogenerated charges, and hence paves a brand new avenue for designing highefficiency photocatalytic reactions.

\section{Methods}

Synthesis of $\mathbf{K}_{\mathbf{4}} \mathbf{N b}_{\mathbf{6}} \mathbf{O}_{\mathbf{1 7}}$ catalysts. $\mathrm{K}_{4} \mathrm{Nb}_{6} \mathrm{O}_{17}$ nanosheet catalysts were synthesized via a conventional solution method with slight modification ${ }^{19}$. In a typical experiment, $0.8 \mathrm{~g} \mathrm{Nb}_{2} \mathrm{O}_{5}$ powder was added into $30 \mathrm{ml} \mathrm{KOH}$ solution $(1 \mathrm{M})$. After vigorous stirring for $30 \mathrm{~min}$, the mixture was transferred into a $45 \mathrm{ml}$ Teflon-lined autoclave, sealed and heated at $220^{\circ} \mathrm{C}$ for $12-24 \mathrm{~h}$. The autoclave was then allowed to cool down to room temperature naturally. The final product was washed with distilled water and ethanol alternately for several times, and then the final product was dried in vacuum at $60^{\circ} \mathrm{C}$ overnight without further treatment

Characterization methods. The samples were characterized by X-ray powder diffraction by a Philips X'Pert Pro Super diffractometer equipped with graphite-monochromatized $\mathrm{Cu}-\mathrm{K} \alpha$ radiation $(\lambda=1.54178 \AA)$. SEM images were performed on a Zeiss Supra 40 field-emission scanning microscope. TEM images were taken on H-7650 (Hitachi, Japan) operating at an acceleration voltage of $100 \mathrm{kV}$. HRTEM images were obtained on JEOL-2010 operating at an acceleration voltage of $200 \mathrm{kV}$. The steady-state ultraviolet-visible absorption spectra were recorded on a Perkin Elmer Lambda 950 spectrophotometer. High-resolution $\mathrm{X}$-ray photoelectron spectroscopy measurements were performed on a VG ESCALAB MK II X-ray photoelectron spectrometer with an excitation source of $\mathrm{Mg} \mathrm{K} \alpha=1253.6 \mathrm{eV}$. Mott-Schottky plot was measured in degassed $0.5 \mathrm{M} \mathrm{Na}_{2} \mathrm{SO}_{4}$ solution $(\mathrm{pH}=6.6)$ at a frequency of $10 \mathrm{~Hz}$ in the dark and the applied potential ranges from -0.5 to $+0.5 \mathrm{~V}$.

TA spectroscopy characterizations. The ultrafast TA measurements were carried out on a modified ExciPro pump-probe spectrometer (CDP) in combination with an amplified femtosecond laser system (Coherent). All the measurements were performed under ambient conditions. The samples under investigation were the $\mathrm{K}_{4} \mathrm{Nb}_{6} \mathrm{O}_{17}$ film immersed in a methanol/water $(1: 4 \mathrm{vol} \%)$ mixed solution and the $\mathrm{K}_{4} \mathrm{Nb}_{6} \mathrm{O}_{17}$ film immersed in a methanol/water $(1: 4 \mathrm{vol} \%)$ mixed solution with a tiny amount of TFA addition $\left(0.5 \mathrm{mll}^{-1}\right)$. The sample cell was mounted on a rotating stage to ensure that the photoexcited volume of the sample was kept fresh during the course of the measurements. Detailed procedures for the femtosecond pump-probe experiments can be found in the Supplementary Methods.

PL and ESR characterizations. The PL emission spectra were obtained on a FLUOROLOG-3-TAU fluorescence spectrometer (Horiba) upon excitation at $315 \mathrm{~nm}$. The ns-domain time-resolved PL spectra (excited at $315 \mathrm{~nm}$; monitored at the 430-nm emission) were recorded on an FLS920 fluorescence spectrometer (Edinburgh). The spin trapping experiments were performed in deoxygenated solutions using a JES-FA200 ESR spectrometer at room temperature. The irradiation experiments were carried out with a Xe lamp (500 W, USHIO Optical Modulex SX-U1501XQ).

Photocatalytic $\mathbf{H}_{\mathbf{2}}$ evolution measurements. Photocatalytic $\mathrm{H}_{2}$ evolution reactions were carried out in a gas-closed circulation system equipped with a vacuum line. Typically, $50 \mathrm{mg}$ photocatalyst powder was dispersed in $200 \mathrm{ml} 20$ vol\% $\mathrm{CH}_{3} \mathrm{OH}$ aqueous solution and then illuminated with a $300 \mathrm{~W}$ Xe lamp (PLS-SXE300/300UV, Trusttech Co., Ltd). The amount of $\mathrm{H}_{2}$ evolution was determined using a gas chromatography (Agilent 7890A).

\section{References}

1. Walter, M. G. et al. Solar water splitting cells. Chem. Rev. 110, 6446-6473 (2010).

2. Blankenship, R. E. et al. Comparing photosynthetic and photovoltaic efficiencies and recognizing the potential for improvement. Science 332, 805-809 (2011).

3. Tachibana, Y., Vayssieres, L. \& Durrant, J. R. Artificial photosynthesis for solar water-splitting. Nat. Photon. 6, 511-518 (2012). 
4. Osterloh, F. E. Inorganic nanostructures for photoelectrochemical and photocatalytic water splitting. Chem. Soc. Rev. 42, 2294-2320 (2013).

5. Maeda, K. \& Domen, K. Photocatalytic water splitting: recent progress and future challenges. J. Phys. Chem. Lett. 1, 2655-2661 (2010).

6. McEvoy, J. P. \& Brudvig, G. W. Water-splitting chemistry of photosystem II. Chem. Rev. 106, 4455-4483 (2006).

7. Barroso, M. et al. The role of cobalt phosphate in enhancing the photocatalytic activity of $\alpha-\mathrm{Fe}_{2} \mathrm{O}_{3}$ toward water oxidation. J. Am. Chem. Soc. 133, 14868-14871 (2011).

8. Simon, T. et al. Redox shuttle mechanism enhances photocatalytic $\mathrm{H}_{2}$ generation on Ni-decorated CdS nanorods. Nat. Mater. 13, 1013-1018 (2014).

9. Reece, S. Y. et al. Wireless solar water splitting using silicon-based semiconductors and earth-abundant catalysts. Science 334, 645-648 (2011).

10. Yang, J., Wang, D., Han, H. \& Li, C. Roles of cocatalysts in photocatalysis and photoelectrocatalysis. Acc. Chem. Res. 46, 1900-1909 (2013).

11. Ran, J., Zhang, J., Yu, J., Jaroniec, M. \& Qiao, S. Z. Earth-abundant cocatalysts for semiconductor-based photocatalytic water splitting. Chem. Soc. Rev. 43, 7787-7812 (2014).

12. McCormick, T. M. et al. Reductive side of water splitting in artificial photosynthesis: new homogeneous photosystems of great activity and mechanistic insight. J. Am. Chem. Soc. 132, 15480-15483 (2010).

13. Du, P. W. \& Eisenberg, R. Catalysts made of earth-abundant elements (Co, Ni, Fe) for water splitting: Recent progress and future challenges. Energy Environ. Sci. 5, 6012-6021 (2012).

14. Nann, T. et al. Water splitting by visible light: a nanophotocathode for hydrogen production. Angew. Chem. Int. Ed. 49, 1574-1577 (2010).

15. Umena, Y., Kawakami, K., Shen, J.-R. \& Kamiya, N. Crystal structure of oxygen-evolving photosystem II at a resolution of $1.9 \AA$ A Nature 473, 55-60 (2011).

16. Compton, O. C., Mullet, C. H., Chiang, S. \& Osterloh, F. E. A building block approach to photochemical water-splitting catalysts based on layered niobate nanosheets. J. Phys. Chem. C 112, 6202-6208 (2008).

17. Townsend, T. K., Sabio, E. M., Browning, N. D. \& Osterloh, F. E. Improved Niobate Nanoscroll Photocatalysts for Partial Water Splitting. ChemSusChem. 4, 185-190 (2011)

18. Bi, W. et al. Spatial location engineering of oxygen vacancies for optimized photocatalytic $\mathrm{H}_{2}$ evolution activity. Small 10, 2820-2825 (2014).

19. Uchida, S., Inoue, Y., Fujishiro, Y. \& Sato, T. Hydrothermal synthesis of $\mathrm{K}_{4} \mathrm{Nb}_{6} \mathrm{O}_{17}$. J. Mater. Sci. 33, 5125-5129 (1998).

20. Yu, J. C., Ho, W., Yu, J., Hark, S. K. \& Iu, K. Effects of trifluoroacetic acid modification on the surface microstructures and photocatalytic activity of mesoporous $\mathrm{TiO}_{2}$ thin films. Langmuir 19, 3889-3896 (2003).

21. Hannaford, P. Femtosecond Laser Spectroscopy (Springer, 2005).

22. Wheeler, D. A. \& Zhang, J. Z. Exciton dynamics in semiconductor nanocrystals. Adv. Mater. 25, 2878-2896 (2013).

23. Buettner, G. R. Spin trapping ESR parameters of spin adducts. Free Radic. Biol. Med. 3, 259-303 (1987).

24. Togashi, H. et al. Analysis of hepatic oxidative stress status by electron spin resonance spectroscopy and imaging. Free Radic. Biol. Med. 28, 846-853 (2000).

25. Pou, S., Cohen, M. S., Britigan, B. E. \& Rosen, G. M. Spin-trapping and human neutrophils. Limits of detection of hydroxyl radical. J. Biol. Chem. 264, 12299-12302 (1989).
26. Ishikawa, A. et al. Oxysulfide $\mathrm{Sm}_{2} \mathrm{Ti}_{2} \mathrm{~S}_{2} \mathrm{O}_{5}$ as a stable photocatalyst for water oxidation and reduction under visible light irradiation $(\lambda \leq 650 \mathrm{~nm})$. J. Am. Chem. Soc. 124, 13547-13553 (2002).

27. Su, J., Guo, L., Bao, N. \& Grimes, C. A. Nanostructured $\mathrm{WO}_{3} / \mathrm{BiVO}_{4}$ heterojunction films for efficient photoelectrochemical water splitting. Nano Lett. 11, 1928-1933 (2011).

28. Liang, Y. H. et al. Synthesis of $\mathrm{Cu}_{2} \mathrm{~S} / \mathrm{K}_{4} \mathrm{Nb}_{6} \mathrm{O}_{17}$ composite and its photocatalytic activity for hydrogen production. Catal. Commun. 46, 128-132 (2014).

29. Iwasita, T. Electrocatalysis of methanol oxidation. Electrochim. Acta 47, 3663-3674 (2002).

\section{Acknowledgements}

This work was financially supported by the National Basic Research Program of China (2015CB932302, 2010CB923300), National Natural Science Foundation of China (21222101, U1432133, 11132009, 21331005, 11321503, U1532265, J1030412, 21173205 and 91127042), Chinese Academy of Sciences (XDB01020000), the Fok Ying-Tong Education Foundation, China (141042) and the Fundamental Research Funds for the Central Universities (WK2060190027, WK2340000063). The authors acknowledge the support of the High Magnetic Field Laboratory of CAS for the ESR characterizations. We also acknowledge J.H. Su for helpful discussions on ESR spectra.

\section{Author contributions}

C.W. conceived the idea and supervised the project. W.B., X.L. and T.J. carried out the sample synthesis, characterizations and photocatalysis measurements. L.Z. and Q.Z. performed the ultrafast TA measurements. Q.Z., Y.L. and L.Z. analysed the TA and PL data. L.Z. performed the theoretical calculations. W.B., Q.Z. and C. W. cowrote the paper. Y.X. supervised the project. All the authors discussed the results and commented on the manuscript.

\section{Additional information}

Supplementary Information accompanies this paper at http://www.nature.com/ naturecommunications

Competing financial interests: The authors declare no competing financial interests

Reprints and permission information is available online at http://npg.nature.com/ reprintsandpermissions/

How to cite this article: $\mathrm{Bi}, \mathrm{W}$. et al. Molecular co-catalyst accelerating hole transfer for enhanced photocatalytic $\mathrm{H}_{2}$ evolution. Nat. Commun. 6:8647 doi: 10.1038/ncomms9647 (2015).

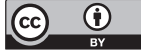

This work is licensed under a Creative Commons Attribution 4.0 International License. The images or other third party material in this article are included in the article's Creative Commons license, unless indicated otherwise in the credit line; if the material is not included under the Creative Commons license, users will need to obtain permission from the license holder to reproduce the material. To view a copy of this license, visit http://creativecommons.org/licenses/by/4.0/ 